\title{
Spirometry in young children: should computer-animation programs be used during testing?
}

\author{
V. Gracchi*,\#, M. Boel*, J. van der Laag*, C.K. van der Ent*
}

Spirometry in young children: should computer-animation programs be used during testing? V. Gracchi, M. Boel, J. van der Laag, C.K. van der Ent. (C) ERS Journals Ltd 2003.

ABSTRACT: Currently, computer-animation programs are frequently used to instruct and stimulate young children in performing maximal expiratory flow/volume (MEFV) curves. The reproducibility and maximal performance of MEFV manoeuvres with and without the use of two computer-animation programs (the "candles" and the "balloon" programs) were evaluated.

Eighty-eight children, aged 4-8 yrs, were randomly assigned to one of the two animation programs. All children performed two series of at least three technically acceptable curves, one series with the incentive and one without, in random order.

With the use of computer-animation programs, a lower proportion of children were able to fulfil international criteria for forced vital capacity (FVC) and forced expiratory volume in one second (FEV1) reproducibility. The use of incentives improved reproducibility and performance of peak expiratory flow (PEF). Performance of FVC decreased significantly in 6-8-yr-old children using the animation programs.

Training with a program for a short period of time before the formal lung-function test may be valuable. According to the results, however, the use of these programs during tests under the guidance of an experienced lung-function technician cannot be routinely recommended because of possible deteriorating effects on reproducibility and performance of forced expiratory manoeuvres.

Eur Respir J 2003; 21: 872-875.
*Dept of Paediatric Pulmonology, University Medical Centre Utrecht, Utrecht, the Netherlands. " Dept of Paediatrics, San Paolo Hospital, University of Milan, Milan, Italy.

Correspondence: C.K. van der Ent Dept of Paediatric Pulmonology

University Medical Centre Utrecht Wilhelmina Children's Hospital

P.O. Box 85090

$3508 \mathrm{AB}$ Utrecht

The Netherlands

Fax: 31302504747

E-mail: k.vanderent@wkz.azu.nl

Keywords: Childhood

forced expiratory manoeuvre

incentives

Received: July 82002

Accepted after revision: January 132003
Maximal expiratory flow/volume (MEFV) curves are the most frequently used lung-function tests in children. They can be very helpful in the diagnosis of obstructive pulmonary diseases and in monitoring the response to therapy. However, MEFV manoeuvres are effort-dependent and skills such as understanding, attention, coordination and cooperation are required. In particular in children aged $<7 \mathrm{yrs}$, maximal and reproducible tests can only be acquired in some cases [1-4].

In recent years, computer-animation programs have been developed in order to instruct and stimulate young children in MEFV manoeuvres. Children are asked to blow out candles, to make planes fly or to blow up balloons on the computer screen. These programs might help children to focus on the task and provide a visual motivation to accomplish an optimal manoeuvre. A wide range of such programs are now available $[5,6]$ but their efficacy has scarcely been studied.

The use of computer-animation programs is supposed to increase the number of young children that can perform reproducible MEFV curves according to the international reproducibility criteria [7, 8]. Moreover, these incentives should increase effort in individual children, leading to higher MEFV parameters. The aim of this study was to evaluate the reproducibility and maximal performance of MEFV manoeuvres in preschool and school-aged children with and without the use of two computer-animation programs (the "candles" and the "balloon" program).

\section{Patients and methods}

MEFV manoeuvres were performed and evaluated in 88 children aged 4-8 yrs who were referred to the authors' paediatric pulmonology dept (University Medical Centre Utrecht) because of symptoms of coughing or wheezing. As it has previously been pointed out that shortness of breath and wheezing are associated with poor forced expiratory volume in one second (FEV1) reproducibility [9], only children who were clinically asymptomatic participated in the study.

MEFV manoeuvres were performed using a pneumotachometer system with a heated Lilly head (MasterScreen Pneumo and Jaeger Masterlab; Erich Jaeger, Hoechberg, Germany). All measurements were corrected for body temperature, pressure and saturated (BTPS) conditions. MEFV manoeuvres were performed with the child sitting in an upright position, keeping the neck in a fixed neutral posture and wearing a noseclip. Adequately sized mouthpieces were provided.

A lung-function technician, experienced in working with children, gave each child individual instructions on the technique of blowing forced expiratory manoeuvres and performed all measurements; some time was dedicated to practicing the technique. On the technician's signal, the children had to fully inhale ("as taking a very big breath") and then exhale ("blowing out all the air, fast and hard"), prolonging expiration as long as possible. Inspiratory manoeuvres were not performed.

The technician evaluated the technical acceptability of MEFV curves by considering rise to peak flow and gradual decline of expiration. Curves had to show a clear and rapid rise to peak flow and a prolonged expiratory curve with gradual flow decrease. Forced expiratory efforts were considered technically unacceptable if deep inhalation was not above tidal volume breathing, a blunt peak was performed, expiration ended abruptly with a sharp drop in flow or if 
interruptions (such as coughing) had occurred during expiratory flow [7, 8]. Technically acceptable MEFV manoeuvres were repeated at least three times. Forced vital capacity (FVC), FEV1 and peak expiratory flow (PEF) for each flow/ volume curve were taken as parameters. Children who were unable to perform acceptable manoeuvres were excluded from the study.

The following European Respiratory Society (ERS) criteria were applied for evaluation of FVC and FEV1 reproducibility: the highest value of FVC and FEV1 "should not exceed the next highest one by more than $5 \%$ or $0.1 \mathrm{~L}$, whichever is greater" [7]. PEF was considered reproducible when the difference between the two highest values did not exceed $5 \%$ of the highest one. Because the $5 \%$ criterion was possibly too strict, especially for young children, reproducibility was also studied according to the 7 and $10 \%$ criterion. For the evaluation of maximal performance, the highest value of the repeated measurements was used.

Two different animation programs were used in this study, which were software applications of the MasterScreen Pneumo system. In the first program (candles) the child had to blow out a series of five burning candles. This program is triggered by peak flow. In the second program (balloon) the child was asked to blow up a balloon as high as possible (triggered by peak flow) and to keep it in the air as long as possible (triggered by FVC). The animation target was achieved when the child reached $120 \%$ of its predicted value for PEF and/or FVC [6].

Each child had to perform two series of MEFV curves: one series with a visual incentive and one series without. An interval of $10-15 \mathrm{~min}$ was given between the two series. Patients were randomised to initially perform either the series with the incentive or the series without, in order to minimise training bias.

\section{Statistical analysis}

In order to study the reproducibility of MEFV curves, the proportion of children who met the reproducibility criteria was calculated. Intrasubject coefficient of variation $(\mathrm{CV} \%=\mathrm{SD} /$ mean $\times 100 \%$, mean \pm SEM of $\mathrm{CV} \%$ for three repeated measurements of FVC, FEV1 and PEF were also calculated. To compare $\mathrm{CV} \%$ and maximal performance obtained with and without the use of incentives, differences between groups were analysed using paired t-tests. A $\mathrm{p} \leqslant 0.05$ was considered to be statistically significant.

\section{Results}

Mean age \pm SD of the 88 children was $5.7 \pm 1.2$ yrs. Fifty eight of the children were male. A total of 47 children had previously performed lung-function tests and 41 had no earlier experience. Children were divided into four groups according to age and experience in lung-function testing: 37 children ( $4.5 \pm 0.5 \mathrm{yrs} ; 25$ inexperienced and 12 experienced) were aged $<6$ yrs and 51 children $(6.5 \pm 0.7 \mathrm{yrs} ; 16$ inexperienced and 35 experienced) were aged 6-8 yrs. No significant difference in sex was found between these groups. A total of 54 children were randomised to the candle program and 34 to the balloon program.

\section{Reproducibility}

As shown in figure 1, a higher proportion of children fulfilled reproducibility criteria of FVC and FEV1 when
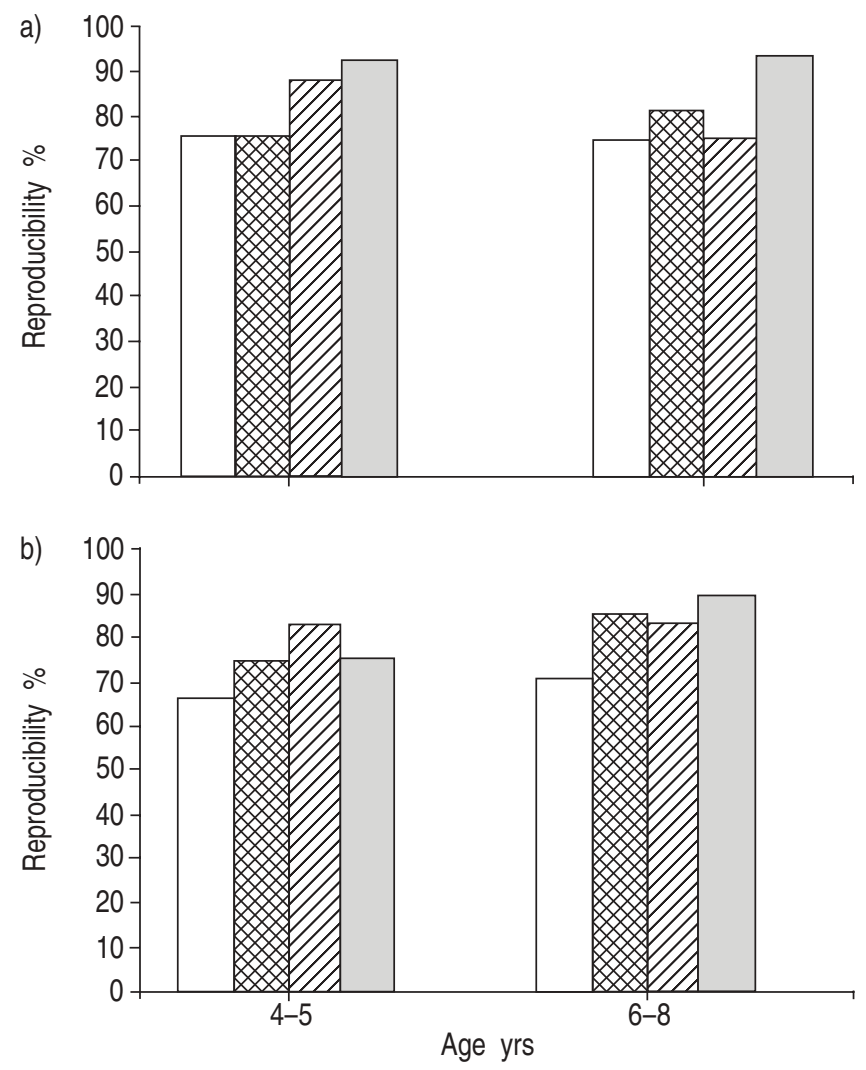

Fig. 1.-Proportion of a) inexperienced and b) experienced children meeting the reproducibility criteria for forced vital capacity (FVC) and forced expiratory volume in one second (FEV1) with and without the use of a computer-animation program during the test (values considered reproducible when differences between the two highest values are $\leqslant 5 \%$ or $\leqslant 100 \mathrm{~mL}$, whichever is greater). Inexperienced children: aged 4-5 yrs, $\mathrm{n}=25$; aged $6-8 \mathrm{yrs}, \mathrm{n}=16$. Experienced children: aged 4-5 yrs, $n=12$; aged $6-8$ yrs, $n=35$. $\square$ : FVC with incentive; FVC without incentive; $\mathbb{Z}$ : FEV1 with incentive; FEV1 without incentive.

incentives were not used (an exception to this observation was found for FEV1 reproducibility in young experienced children: 75 without versus $83.3 \%$ with the animation program). Reproducibility of PEF was higher with the incentives in all children (table 1). When the criterion for reproducibility was set at 7 or $10 \%$, instead of $5 \%$, the same trends were observed. Although a higher proportion of children reached reproducibility with these criteria, the use of the incentive did not improve reproducibility of FVC and FEV1. Intra-subject $\mathrm{CV} \%$ of the repeated parameters are shown in table 2 . Use of the programs did not significantly improve the reproducibility of any of the parameters.

\section{Performance}

With the use of incentives, all groups of children performed significantly higher PEF values. No beneficial effects of the two incentives were observed on any other MEFV parameter. In school-aged, experienced children the use of the animation program significantly decreased the performance of FVC (table 2).

\section{Discussion}

In the present study it was observed that reproducibility of MEFV curves does not improve and, in some instances, might 
Table 1. - Proportion of children meeting the reproducibility criteria with and without the use of a computer-animation program during the test

\begin{tabular}{|c|c|c|c|c|c|c|c|c|}
\hline & \multicolumn{4}{|c|}{ With use of program } & \multicolumn{4}{|c|}{ Without use of program } \\
\hline & $\leqslant 5 \%$ & $\leqslant 7 \%$ & $\leqslant 10 \%$ & $\leqslant 100 \mathrm{~mL}$ & $\leqslant 5 \%$ & $\leqslant 7 \%$ & $\leqslant 10 \%$ & $\leqslant 100 \mathrm{~mL}$ \\
\hline \multicolumn{9}{|c|}{ Inexperienced children } \\
\hline \multicolumn{9}{|l|}{ 4-5 yrs \# } \\
\hline FVC & 52.0 & 64.0 & 80.0 & 76.0 & 60.0 & 76.0 & 80.0 & 76.0 \\
\hline FEV1 & 64.0 & 68.0 & 88.0 & 88.0 & 72.0 & 88.0 & 92.0 & 92.0 \\
\hline PEF & 48.0 & 60.0 & 76.0 & & 40.0 & 56.0 & 80.0 & \\
\hline \multicolumn{9}{|l|}{$6-8 \mathrm{yrs}^{\bullet}$} \\
\hline FVC & 75.0 & 81.3 & 93.8 & 75.0 & 62.5 & 87.5 & 93.8 & 81.3 \\
\hline FEV1 & 75.0 & 81.3 & 87.5 & 75.0 & 68.8 & 93.8 & 93.8 & 93.8 \\
\hline $\mathrm{PEF}$ & 56.3 & 75.0 & 87.5 & & 50.0 & 62.5 & 31.3 & \\
\hline \multicolumn{9}{|c|}{ Experienced children } \\
\hline \multicolumn{9}{|c|}{$4-5 \mathrm{yrs}^{+}$} \\
\hline FVC & 58.3 & 75.0 & 83.3 & 66.7 & 66.7 & 66.7 & 75.0 & 75.0 \\
\hline FEV1 & 66.7 & 83.3 & 83.3 & 83.3 & 50.0 & 66.7 & 83.3 & 75.0 \\
\hline $\mathrm{PEF}$ & 58.3 & 75.0 & 83.3 & & 41.7 & 41.7 & 50.0 & \\
\hline \multicolumn{9}{|l|}{$6-8 \mathrm{yrs}^{\S}$} \\
\hline FVC & 60.0 & 74.3 & 88.6 & 71.4 & 77.1 & 88.6 & 91.4 & 85.7 \\
\hline FEV1 & 74.3 & 82.9 & 94.3 & 82.9 & 85.7 & 91.4 & 97.1 & 88.6 \\
\hline PEF & 62.9 & 74.3 & 85.7 & & 57.1 & 77.1 & 91.4 & \\
\hline
\end{tabular}

Different reproducibility criteria are considered: curves considered to be reproducible when differences between the two highest values are $\leqslant 5, \leqslant 7, \leqslant 10 \%$ and $\leqslant 100 \mathrm{~mL}$. FVC: forced vital capacity; FEV1: forced expiratory volume in one second; PEF: peak expiratory flow. ${ }^{\#}: \mathrm{n}=25 ;{ }^{\uparrow}: \mathrm{n}=16 ;{ }^{+}: \mathrm{n}=12 ;{ }^{\S}: \mathrm{n}=35$.

even worsen with the use of computer-animation programs, both in preschool and school-aged children. Although the programs helped children to perform better PEF values, in school-aged children with lung-function testing experience, the use of animation programs resulted in lower FVC values.

MEFV curves represent a unique tool in the diagnosis and follow-up of many lung diseases. Most children aged $>6$ yrs, even those with no previous experience, can perform acceptable FVC manoeuvres, but in younger children, more problems can be encountered, especially concerning cooperation and motivation [1-4]. Because of the importance of pulmonary function testing, one of the major issues in paediatric pulmonology is to increase its clinical applicability in early life, mainly by minimising inter- and intra-subject variability, by standardising equipment and methodology and by improving training facilities [10]. It is therefore understandable that in the past few years much interest has been shown in visual incentives as of possible assistance in coaching children to perform acceptable forced expiratory manoeuvres. Computer-animation programs can be helpful in explaining to young children, without previous experience, how to blow MEFV curves. Nevertheless, to date, investigating the usefulness

Table 2.-Results of maximal expiratory flow/volume (MEFV) parameters and coefficient of variation (CV\%) of the three repeated measurements with and without the use of a computer-animation program during the test

\begin{tabular}{|c|c|c|c|c|c|c|}
\hline & \multicolumn{2}{|c|}{ With use of program } & \multicolumn{2}{|c|}{ Without use of program } & \multirow[t]{2}{*}{ p-value ${ }^{\#}$} & \multirow[t]{2}{*}{ p-value } \\
\hline & mean $\pm \mathrm{SD}$ & $\mathrm{CV} \%$ & mean \pm SD & $\mathrm{CV} \%$ & & \\
\hline \multirow{2}{*}{\multicolumn{7}{|c|}{ Inexperienced children }} \\
\hline & \multicolumn{6}{|c|}{ 4-5 $\mathrm{yrs}^{+}$} \\
\hline FVC L & $1.24 \pm 0.33$ & 6.20 & $1.27 \pm 0.30$ & 6.30 & 0.17 & 0.92 \\
\hline FEV1 L & $1.16 \pm 0.29$ & 5.33 & $1.16 \pm 0.28$ & 4.93 & 0.89 & 0.63 \\
\hline PEF $L \cdot s^{-1}$ & $2.70 \pm 0.60$ & 6.31 & $2.55 \pm 0.60$ & 6.35 & $<0.01^{f}$ & 0.74 \\
\hline \multicolumn{7}{|l|}{$6-8 \mathrm{yrs}^{\S}$} \\
\hline FVC L & $1.37 \pm 0.41$ & 5.53 & $1.42 \pm 0.45$ & 5.00 & 0.25 & 0.64 \\
\hline FEV1 L & $1.28 \pm 0.30$ & 4.64 & $1.26 \pm 0.30$ & 5.06 & 0.57 & 0.69 \\
\hline $\mathrm{PEF} \mathrm{L} \cdot \mathrm{s}^{-1}$ & $2.97 \pm 0.69$ & 7.13 & $2.69 \pm 0.67$ & 8.45 & $<0.01^{f}$ & 0.47 \\
\hline \multirow{2}{*}{\multicolumn{7}{|c|}{ 4-5 yrs }} \\
\hline & & & & & & \\
\hline FVC L & $1.27 \pm 0.32$ & 9.28 & $1.30 \pm 0.36$ & 5.53 & 0.43 & 0.27 \\
\hline FEV1 L & $1.15 \pm 0.31$ & 5.72 & $1.13 \pm 0.32$ & 5.60 & 0.43 & 0.25 \\
\hline $\mathrm{PEF} \mathrm{L} \cdot \mathrm{s}^{-1}$ & $2.68 \pm 0.93$ & 6.45 & $2.46 \pm 0.83$ & 8.65 & $0.04^{f}$ & \\
\hline \multicolumn{7}{|l|}{$6-8 \mathrm{yrs}^{\text {ตๆ }}$} \\
\hline FVC L & $1.58 \pm 0.22$ & 5.72 & $1.66 \pm 0.27$ & 4.87 & $<0.01^{f}$ & 0.39 \\
\hline FEV1 & $1.46 \pm 0.23$ & 5.39 & $1.47 \pm 0.24$ & 3.89 & 0.68 & 0.18 \\
\hline PEF $L \cdot \mathrm{s}^{-1}$ & $3.57 \pm 0.70$ & 5.85 & $3.42 \pm 0.73$ & 5.21 & $<0.01^{f}$ & 0.51 \\
\hline
\end{tabular}

FVC: forced vital capacity; FEV1: forced expiratory volume in one second; PEF: peak expiratory flow. ${ }^{+}: \mathrm{n}=25 ;{ }^{\S}: \mathrm{n}=16 ;{ }^{\# \#}: \mathrm{n}=12$; ": $\mathrm{n}=35$. " : p-value of paired samples t-test between results with and without use of the program; ${ }^{\text {" }}$-value of paired samples t-test between $\mathrm{CV} \%$ with and without use of the program; ${ }^{f}$ : statistically significant. 
of these facilities in terms of curve reproducibility and performance has not been given much attention.

In this study, a lower proportion of children met the reproducibility criteria of FVC and FEV1 when incentives were used, while a higher proportion met reproducibility criteria for PEF. The slightly higher reproducibility observed for FEV1 in young, experienced children using the programs may indicate a possible benefit for their use in this selected group. In the same group, however, the use of an incentive led to worse FVC reproducibility. Results in this group are therefore contradictory and may be due to the small sample size.

The animation programs were helpful in stimulating the performance of children during the very first part of the MEFV curve; with the use of the incentives, PEF values were significantly higher in all patients. However, no improvement of FEV1 performance was shown. Of particular importance is the fact that in young, inexperienced children the only parameter to be improved by the use of incentives was PEF. Moreover, FVC values were significantly lower in schoolaged, experienced children using the animation programs. These results may be due to the fact that PEF is the main target in the animation programs and children stop their MEFV manoeuvres as soon as the target is achieved. In older experienced children, the incentives might even be a distraction and lead to worse MEFV curves. Although the computer screen is helpful in explaining to a child "how to blow", it seems to be more attractive to children to play a game, rather than perform maximal and reproducible manoeuvres.

The improvement in reproducibility and performance of PEF with the incentives can hardly be an advantage. PEF is a measure of cooperation and effort but its importance in the evaluation of peripheral airway obstruction or restrictive diseases is limited when compared with FEV1 and FVC [11, 12]. Therefore, the use of an animation program that only improves PEF values cannot be justified if it leads to worse reproducibility or FVC performance.

Until now, no data comparing reproducibility and performance of MEFV manoeuvres with and without the use of incentives were available. Recently, VILOZNI et al. [5] stated that the use of a computer-animated system facilitates successful spirometry in children aged 3-6 yrs. However, the aim of that study was to compare two different computeranimation programs (a new ice-shaped incentive and the candle program) and they did not compare the data with "noincentive" values. The authors demonstrated that the new incentive led to a higher number of acceptable curves than using an incentive that was familiar to children, such as the candle program. In the present study, a different issue was addressed: are the incentives (candles or the balloon) really useful in obtaining curves that are better, in terms of reproducibility and results, than the ones obtained without a visual incentive, but with only the support of a trained and qualified technician? In order to answer this question, the curves performed by the same children with and without the use of animation programs were compared. Moreover, only differences in acceptable curves (all children could blow acceptable curves even with no incentive when adequately instructed) were evaluated and the primary outcome for VILOZNI et al. [5] was used to compare the percentages of children who could blow acceptable curves. The results obtained by comparing MEFV curves blown with and without incentives do not show elements that confirm the statements of VILOZNI et al. [5] over usefulness of computer-animation programs. In particular, no substantial improvement was shown in MEFV curves blown by inexperienced children with the use of animation programs.

This study shows that the use of an animation program is not always an advantage, not even in young, inexperienced children. These incentives can be helpful in instructing young children on how to blow and the training provided with these programs during a short period of time before the formal lung function test might be valuable. However, according to the present results the routine use of these programs during the test cannot be recommended.

Acknowledgements. The authors would like to thank I. Prins and Y. Tersmette for performing the lung function tests.

\section{References}

1. Kanengiser S, Dozor AJ. Forced expiratory manoeuvres in children aged 3 to 5 years. Pediatr Pulmonol 1994; 18: 144 149.

2. Crenesse D, Berlioz M, Bourrier T, Albertini M. Spirometry in children aged 3 to 5 years: reliability of forced expiratory manoeuvres. Pediatr Pulmonol 2001; 32: 56-61.

3. Eigen H, Bieler H, Grant D, et al. Spirometric pulmonary function in healthy preschool children. Am J Respir Crit Care Med 2001; 163: 619-623.

4. Arets HGM, van der Ent CK. Flow/volume measurements from childhood to adulthood. Monaldi Arch Chest Dis 2000; 55: $348-352$

5. Vilozni D, Barker M, Jellouschek H, Heimann G, Blau H. An interactive computer-animated system (SpiroGame) facilitates spirometry in preschool children. Am J Respir Crit Care Med 2001; 164: 2200-2205.

6. LAB user manual-Pulmology. Version 4.5. Hoechberg, Germany, Erich Jaeger GmbH, 2001; pp. 24-25.

7. Quanjer PH, Tammeling GJ, Cotes JE, Pedersen OF, Peslin R, Jernault JC. Lung volumes and forced ventilatory flows. Report Working Party. Standardization of lung function tests. Eur Respir J 1993; 6: Suppl. 16, 5s-40s.

8. American Thoracic Society. Standardization of spirometry, 1994 update. Am J Respir Crit Care Med 1995; 152: 11071136.

9. Studnicka M, Frischer T, Neumann M. Determinants of reproducibility of lung function tests in children aged 7 to 10 years. Pediatric Pulmonol 1998; 25: 238-243.

10. Stocks J. Respiratory function testing in early childhood: where have we come from and where are we going? Pediatric Pulmonol 1999; 18: Suppl., 24s-28s.

11. Quanjer PH, Lebowitz MD, Gregg I, Miller MR, Pedersen OF Peak expiratory flow: conclusions and recommendations of a Working Party of the European Respiratory Society. Eur Respir J 1997; 10: Suppl. 24, 2s-8s.

12. Paggiaro PL, Moscato G, Giannini D, Di Franco A, Gherson G. Relationship between peak expiratory flow (PEF) and FEV1. Eur Respir J 1997; 10: Suppl. 24, 39s-41s. 